\title{
Desafios do uso da Tecnologia Informação e Comunicação na Inclusão Digital de Professores de uma Escola Pública Quilombola
}

\author{
Liziany Müller ${ }^{1}$, Giséli Duarte Bastos ${ }^{1}$, Andrieli Hedlund Bandeira ${ }^{1}$, Cláudia \\ Smaniotto Barin ${ }^{1}$, Débora Marshall ${ }^{1}$, Jean Cecchin Biondo ${ }^{1}$
}

${ }^{1}$ Núcleo de Tecnologia Educacional, Universidade Federal de Santa Maria. Avenida Roraima ${ }^{\circ} 1000.97105-900$.

\author{
lizianymecead.ufsm.br, giseli.bastos@ufsm.br, \\ andrieli hedlundehotmail.com, claudiabarin@hotmail.com, \\ deboraeadufsmegmail.com.br, jeanbiondo@hotmail.com
}

\begin{abstract}
The scope of this work is the discussion of digital inclusion and reflection on the integration of information and communication technologies (ICT) as tools to support teaching in the School Hall Albino Manuel Carvalho, aiming to democratize access to information respecting the peculiarities and particularities of african-Brazilian culture of the Quilombo de São Miguel. The methodology was qualitative and exploratory research evaluated data from the questionnaires survey type. The results point to the challenge of ICT use in education both in regard to adequate training of teachers in planning and methodology to promote student motivation and stimulation of the teaching-learning process linked to social realities.
\end{abstract}

Resumo. O escopo deste trabalho é a discussão acerca da inclusão digital e a reflexão sobre a inserção das TIC como ferramentas de apoio pedagógico na Escola Municipal Manuel Albino Carvalho, visando a democratização ao acesso da informação respeitando as peculiaridades e particularidades da cultura afro-brasileira do Quilombo de São Miguel. A metodologia foi da pesquisa exploratória qualitativa sendo os dados avaliados a partir da aplicação de questionários tipo survey. Os resultados obtidos apontam para o desafio do uso das TIC no ensino tanto no que tange a capacitação adequada dos professores quanto ao planejamento e a metodologia que promovam a motivação dos estudantes e dinamização do processo ensino-aprendizagem vinculados às realidades sociais.

\section{Introdução}

A evolução social do homem confunde-se com as tecnologias desenvolvidas e seus avanços em cada época em diferentes períodos da história da humanidade (Kenski 2010). Ainda para esse autor, a evolução tecnológica não se restringe apenas aos novos usos de determinados equipamentos e produtos, ela altera comportamentos, transforma a maneira de pensar, sentir e agir, não apenas o comportamento individual, mas o de todo o grupo social.

O caminho para a educação perpassa por todas as atividades humanas, por isso seu objetivo maior deve ser propiciar o pleno desenvolvimento dos indivíduos levandoos à humanização, pois, a educação num sentido amplo, cumpre uma inulidível função 
de socialização desde que a configuração social da espécie se transforma em um fator decisivo da hominização e em especial da humanização do homem (Gómez 1998; Sacristán; Gómmez 1998).

$\mathrm{O}$ avanço da tecnologia permitiu que o acesso à informação se tornasse muito mais rápido e fácil, e, como não poderia ser diferente, o meio acadêmico também foi atingido, o giz, o quadro negro, o caderno e os livros não são mais as únicas ferramentas utilizadas em sala de aula (Almeida; Prado, 2009). As atuais tecnologias de informação e comunicação (TIC) apresentam novas possibilidades para o indivíduo vivenciar processos criativos, estabelecendo aproximações e associações inesperadas, juntando significados anteriormente desconexos e ampliando a capacidade de interlocução por meio das diferentes linguagens que tais recursos propiciam (Martinsi 2008).

Há um novo panorama educacional gerado pela entrada das TIC que vêm ocasionando, diferentes experiências e ampliações metodológicas para esta esfera, estas tecnologias estão transformando, de forma significativa, a maneira de agir e refletir na educação (Soffa; Torres, 2009). Com o avanço crescente das tecnologias nas últimas décadas os paradigmas da educação tradicional baseados na educação compulsória e massiva pautada nos pares transmissão-recepção, sequência-linearidade, entreguerecebido, característicos da educação bancária (Freire 2006), necessitam ser resignificados. Assim novos espaços e maneiras de pensar e fazer a educação são exigidos na sociedade da informação.

No Brasil, onde a exclusão escolar (evasão, repetência) é um elemento estruturante do sistema de ensino, redimensionar o pensar-fazer pedagógico, incorporando as TIC, pressupõe um passo no processo de socialização de um bem cultural e viabilização da educação que se faz necessária para uma sociedade em que o conhecimento ainda se limita drasticamente às minorias (Silva 2007). Promover a inclusão digital é algo que, além das questões sociais envolvidas, é um direito que o cidadão tem de participar das tecnologias existentes, ter uma educação mais atualizada, capacitação profissional, maior competitividade no mercado, etc (Costa et al. 2007). Para Aquino (2008, p.97), "incluir é um dispositivo inteligente, a partir do qual os indivíduos de diferentes culturas e grupos sociais podem experimentar, reinventar e agir sobre a informação".

Nesse sentido, as TIC representam um recurso que pode ajudar a reverter situações em que se encontram as comunidades que não estão interconectadas, sobretudo com os grandes centros, mas isto só será possível se esses instrumentais forem incorporados considerando os referencias educacionais, econômicos e culturais dessas comunidades (Cavalcante et al. 2009).

A questão da diversidade real e efetiva nos enfoques educacionais e curriculares necessita de uma ampla discussão em diferentes esferas e nas comunidades quilombolas isso não é diferente. No quilombo São Miguel, a necessidade do ensino formal identificada pela população, que busca essa inserção no processo educacional dos seus filhos, procurando uma maior inclusão social, tem o contraponto da exclusão do entorno imediato, com o estabelecimento de espaços claramente divididos entre o cotidiano e o saber da comunidade, essencial para a formação dos mais novos e para o sentido de comunidade tradicional, e a escola como símbolo do ensino formal, do "externo" responsável pela inclusão cidadã. Esta divisão tão clara impede o diálogo entre esses dois ambientes sociais (comunidade, escola), cujos conhecimentos podem ser complementares, ampliando a formação e as possibilidades com o compartilhamento e o 
aprendizado conectivo, ampliando sobremaneira a visão de mundo não só dos alunos, mas também da escola pluricultural que temos hoje.

Nesse contexto, em um estudo sobre o papel da escola em comunidades quilombolas evidenciou-se que "escola é um espaço privilegiado de construção de conhecimento e a sociedade brasileira possui uma dívida com relação à reconstrução da identidade e autoestima da população afrodescendente". As comunidades quilombolas despertaram uma série de questões socioeconômicas, espaciais, jurídicas e culturais que passaram a fazer parte da discussão sobre o que representam os quilombos contemporâneos na atualidade e sobre a sua efetiva inserção cidadã. Entretanto, para que essa inserção se realize, não basta que a sociedade obtenha o conhecimento sobre estes grupos, mas também que a população quilombola se veja dentro da sociedade atual, que o conhecimento ocidentalizado, eurocêntrico, presente nas escolas formais abra um espaço significativo para a vivência e educação destas comunidades (Paré; Oliveira; Velloso, 2007).

A inserção das TIC nas escolas das comunidades quilombolas pode representar uma efetiva inclusão social desses sujeitos, porém, segundo Almeida; Valente (2005) tal prática "impõe mudanças nos métodos de trabalho dos professores, gerando modificações no funcionamento das instituições e no sistema educativo".

A necessidade do professor dominar os recursos tecnológicos pode ser entendido como exigência de alfabetização tecnológica deste profissional e não pode ser compreendida apenas como o uso mecânico dos recursos tecnológicos, mas deve abranger também o domínio crítico da linguagem tecnológica para que os docentes atuem no preparo de cidadãos capazes de lidar com o avanço tecnológico, participando dele e de suas consequências.(Sampaio; Leite, 1999). A inserção de tecnologias no processo de ensino-aprendizagem sobretudo requer uma nova pedagogia que favoreça tanto o aprendizado personalizado quanto o cooperativo em rede. Entretanto, para que a potencialidade informativa e comunicativa das redes possa ser explorada é necessário que os professores estejam minimamente familiarizados com essas tecnologias e suas possibilidades pedagógicas, neste sentido, é fundamental a redefinição do papel do professor (Kenski 2003).

Este trabalho tem objetivo de promover a discussão sobre inclusão digital bem como reflexões sobre a inserção das TIC como ferramentas de apoio pedagógico na Escola Municipal Manuel Albino Carvalho proporcionando a democratização ao acesso da informação, levando em consideração as peculiaridades e particularidades da cultura afro-brasileira do Quilombo de São Miguel.

\section{Material e Métodos}

O trabalho foi desenvolvido na Escola Municipal Manuel Albino Carvalho, localizada no Quilombo São Miguel na zona rural ao Norte de Restinga Seca e a Leste Santa Maria, cortado pela rodovia RS 149, próximo aos rios Vacacaí Mirim e Jacuí.

Segundo historiadores dizem que São Miguel é a segunda comunidade, em quantidade, de negros no RS, e é tida como uma modalidade de organização social alternativa ao sistema escravista e, de forma mais geral, de resistência as pressões de uma sociedade racista. São Miguel é um lugar onde circulam homens e mulheres em alianças matrimoniais que praticamente fecham o ciclo de relações, e de forma mais geral, as mulheres circulam para morar no reduto dos pais do marido, mas o inverso também ocorre com regularidade.

Atualmente o quilombo de São Miguel possui 153 famílias, cada uma com três pessoas em média, totalizando 459 pessoas. A principal atividade econômica é o 
trabalho nas lavouras de fazendas vizinhas, no geral é uma comunidade de classe médiabaixa.

A escola atende a comunidade quilombola e foi fundada em 1960, atualmente possui a Educação Infantil (Pré-Escolar A e B), Ensino Fundamental $\left(1^{\circ}\right.$ ano ao $\left.9^{\circ}\right)$ do Ensino Fundamental. A escola tem objetivo de proporcionar aos estudantes situações que contribuam para o desenvolvimento social, cognitivo, afetivo, psicomotor, atenção e o raciocínio lógico, dentro de uma pedagogia lúdica e de livre expressão, levando-as à estruturação das noções básicas na formação da sua personalidade e de caráter capazes de auxiliá-las na leitura e na escrita do mundo.

A escola possui seis (6) salas de aula, uma (1) sala de professores, uma (1) secretaria, uma (1) biblioteca com reduzido espaço, pois também funciona nesse espaço a videoteca, um (1) ginásio de esportes em construção e um (1) laboratório de informática. Ressalta-se que, a escola não possui linha telefônica nem acesso à internet. Em termos de equipamentos, a escola possui 20 computadores, no entanto, apenas 15 estão em uso, um retroprojetor, que é pouco utilizado, dois mimeógrafos e uma impressora multifuncional.

O corpo docente é constituído por 20 professores especialistas em educação. A designação dos docentes é feita pela entidade mantenedora responsável (Prefeitura de Restinga Seca). Entretanto, os professores desta escola afirmam não terem competência e habilidades para trabalharem com as TIC em sala de aula, uma vez que não tiveram em seus currículos.

O corpo discente é constituído por cerca de 150 alunos, regularmente matriculados. $\mathrm{O}$ aluno, individualmente ou em grupo, conta em especial, com a atenção do professor conselheiro de turma. $\mathrm{Na}$ ocasião da matrícula, o aluno assume o compromisso de observar as disposições regimentais da escola.

Quanto ao tipo de pesquisa, ela pode ser compreendida como um estudo dentro da modalidade de uma pesquisa-ação, num paradigma construtivista de uma pesquisa qualitativa. Conforme o nível e a modalidade da pesquisa, ela caracteriza-se como uma pesquisa-ação, apoiada em Gil (2002). O autor afirma que neste nível de investigação é permitido ao investigador realizar transformações sociais em grupos por meio da participação direta em todas as fases do estudo.

O público alvo do estudo foram os professores da Escola Municipal Manuel Albino Carvalho.

Como instrumentos de coleta de dados foi adotado um questionário tipo Survey com questões fechadas e abertas (Quadro 1), para mapear a realidade do corpo docente frente as tecnologias da informação e comunicação. A aplicação do questionário deu-se no mês de dezembro de 2011.

Quadro 1 - Questionário aplicado para os professores da Escola Municipal Manuel Albino Carvalho.

\begin{tabular}{|ll|}
\hline & \\
& \\
& \\
\hline 1. & Questões \\
\hline 2. & Qual sua idade? \\
\hline 3. & Qual o regime de trabalho na Escola Manuel Albino Carvalho? \\
\hline $4 . \quad$ Você trabalha em outro local? \\
\hline 5. & Qual seu nível de Formação? \\
\hline
\end{tabular}




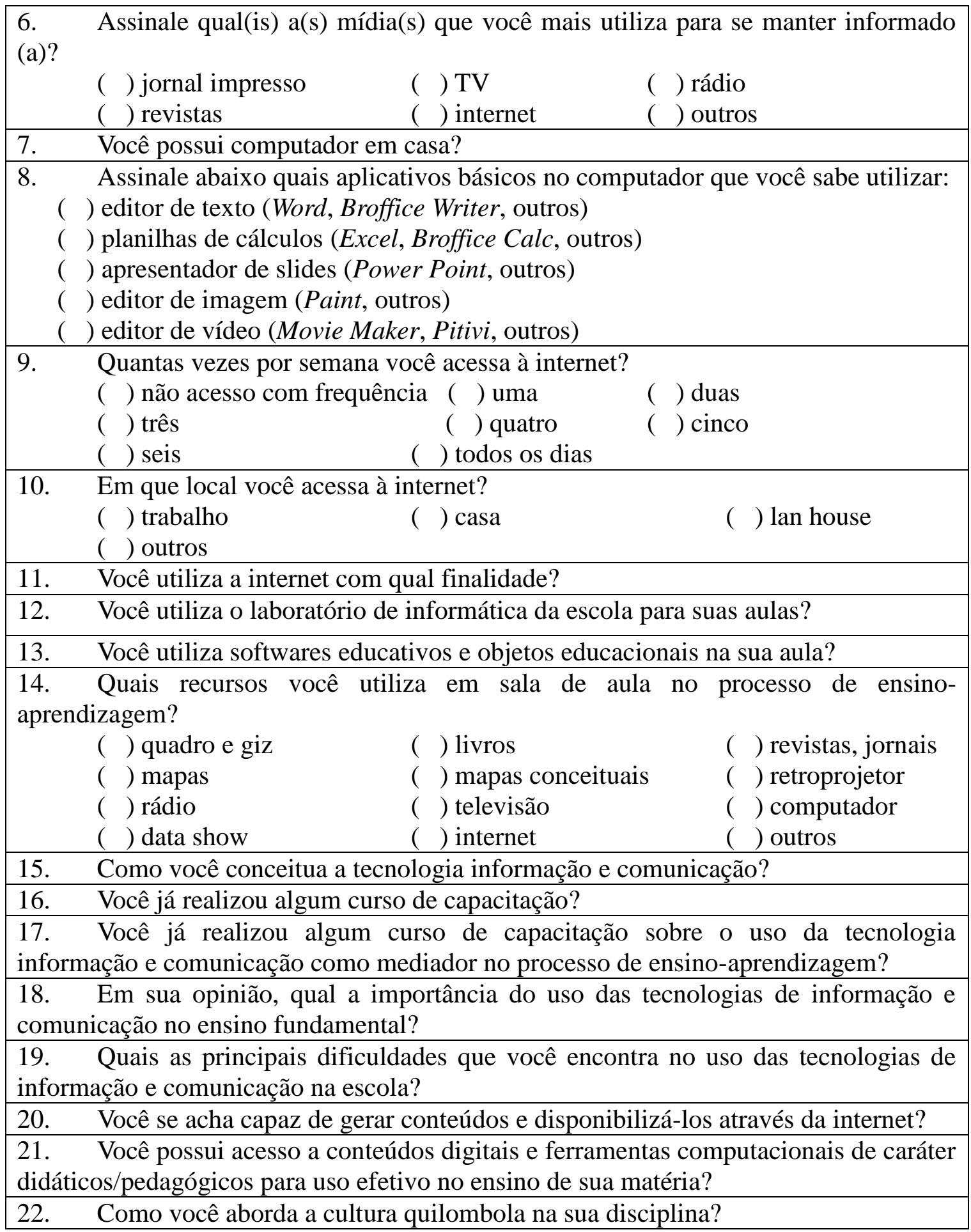

\section{Resultados e Discussão}

Conhecer o perfil e auxiliar na alfabetização tecnológica dos professores das escolas públicas da zona rural que atendem a comunidades quilombola é fundamental para o aprimoramento do processo de ensino-aprendizagem dos estudantes. Uma vez que, atualmente, o RS apresenta diversas comunidades remanescentes de quilombos, que se encontram numa situação de expropriação de suas terras e de difícil 
sobrevivência, sendo a educação um dos caminhos para desenvolvimento dessas comunidades.

O survey apontou que a maioria dos professores $(75 \%)$ possuem idade superior a 35 anos, a maioria são do sexo feminino, trabalham 20 horas semanais na escola (70\%), porém, 70\% trabalham em outra escola (Questão 1 a 4). Cerca de $60 \%$ dos professores possuem curso superior, sendo que 63\% possuem especialização, e, apenas $13 \%$ mestrado e nenhum possui doutorado (Questão 5).

Os professores apontaram que utilizam as mídias jornal impresso (82\%), internet (75\%), televisão (75\%), para se manter informado (Questão 6). E 94\% possuem computador em casa, e, os aplicativos mais utilizados pelos professores são editor de texto (92\%) e apresentador de slides (50\%), (Questões 7 e 8). Cerca de 57\% acessam diariamente à internet, mas $18 \%$ não acessam com freqüência à internet, e, $94 \%$ dos professores acessam à internet em casa (Questões 9 e 10). Entre as finalidades de acesso, $82 \%$ dos professores utilizam a internet para fazer pesquisas para a elaboração de suas aulas (Questão 11).

Assim, os resultados indicam que a maioria dos professores utilizam as TIC potencializando o seu uso como recurso para a prática docente, proporcionando fontes bibliográficas, recursos didáticos e informações, formando redes de produção colaborativa de conhecimento acadêmico, científico e profissional, desempenhando um papel primordial na formação sócio-educacional dos sujeitos quilombolas. De acordo com Rosini (2007) essa nova cidadania da cultura informatizada requer novos hábitos intelectuais de simbolização, formalização do conhecimento, manuseio dos signos e das representações, o que também exige uma nova gestão social do conhecimento, apoiada num modelo digital explorado de forma interativa. Para esse autor, desprezar ou mesmo minimizar neste momento histórico a importância das tecnologias na educação presencial é errar de século, tornando-se assim, fundamental a fluência tecnológica do professor.

Cerca de $69 \%$ dos professores utilizam o laboratório de informática em suas aulas, e citaram que fazem atividades como: digitação de texto, tradutor, visualizar imagens e slides em apresentador de texto (Questão 12). Kenski (2010) ressalta que a educação é um mecanismo poderoso de articulação das relações entre poder, conhecimento e tecnologias, e, conforme Sampaio; Leite (1999) o papel da educação deve voltar-se também para a democratização do acesso ao conhecimento, produção e interpretação das tecnologias, suas linguagens e conseqüências.

Entretanto, $100 \%$ dos professores não utilizam softwares e objetos de aprendizagem no laboratório de informática (Questão 13). Esse fato acomete a falta de habilidade dos professores ainda nesse novo processo educativo que inclui a tecnologia, mostrando ser necessário um maior treinamento dos professores, pois, conforme Kenski (2010) a escola deve pautar-se pela intensificação das oportunidades de aprendizagem e autonomia dos estudantes em relação à busca de conhecimentos, da definição de seus caminhos, da liberdade para que possam criar oportunidades e serem os sujeitos da própria existência.

Sampaio; Leite (1999) revelam que para isso torna-se necessário preparar o professor para utilizar pedagogicamente as tecnologias na formação de cidadãos que deverão produzir e interpretar as novas linguagens do mundo atual e futuro. Entretanto, não basta apenas ter acesso a esses instrumentos, sobretudo, é preciso saber utilizá-los eficazmente. 
Os recursos utilizados para mediar o processo de ensino-aprendizagem pelos professores apontados foram: quadro de giz (100\%), livros (98\%), revistas e jornais (63\%), televisão (63\%), computador/laboratório de informática (50\%), mapas (38\%), mapas conceituais (25\%), materiais de pesquisas de internet feitas pelo professor (19\%), rádio (19\%). A alternativa "outros" foi assinalada por $25 \%$ dos professores, e representam: dicionário, CD, vídeos, material reciclado, etc (Questão 14). Evidencia-se que diante da necessidade de serem diversificadas as possibilidades e formas de agir e aprender, as tecnologias de informação e comunicação (TIC) abrem oportunidades para a ação dos indivíduos e a diversificação e transformação nos ambientes de aprendizagem (Martinsi, 2008).

Estes resultados indicam que a maioria dos professores utilizam as TIC como recurso para a prática docente na escola quilombola. O uso criativo das tecnologias pode auxiliar os professores a transformar o isolamento, a indiferença e a alienação com o que costumeiramente os estudantes frequentam as salas de aula, em interesse e colaboração, por meio dos quais eles aprendem a aprender, a respeitar, a aceitar, a serem pessoas melhores e cidadãos participativos (Kenski, 2010).

Buscando verificar o nível de fluência tecnológica dos professores, questionouse o conceito de TIC (Questão 15). Foi observado que os professores sabem conceituar, porém não possuem com clareza maneiras de introduzi-las em sala de aula, principalmente, devido a escassez de recursos tecnológicos na escola.

Os professores foram questionados quando ao conceito de TIC, entre elas destacamos:

"É uma ferramenta que pode ser utilizada no processo de ensinoaprendizagem"; "Uma necessidade no contexto atual"; "Atualmente tornou-se fundamental no processo de ensino-aprendizagem, é uma forma atrativa e que faz com que o aluno se interesse em conhecer, pois ele domina e esta habituado a conviver, faz parte do seu cotidiano. Portanto a tecnologia de informação e comunicação é a forma mais moderna de comunicar-se utilizando os novos instrumentos tecnológicos"; "A tecnologia são os meios dinâmicos e novos usados na educação, mas não é a realidade dos nossos alunos";

Os professores ressaltam que não tiveram formação curricular sobre o uso de tecnologias em sala de aula. Assim, é importante evidenciar que os professores devem ser capacitados quanto ao uso das tecnologias, para que possam utilizá-las no processo educativo.

Entretanto, cerca de 50\% dos professores da escola realizaram um curso de capacitação (Questão 16), mas apenas $12 \%$ possuem capacitação em TIC (Questão 17). A prática docente de qualidade tem exigido do professor formação continuada e habilidades que estão para além da dimensão curricular, as quais incluem o uso das TIC como um conteúdo de aprendizagem. São habilidades capazes de auxiliar o docente a romper com modelos existentes em prol da adoção crítica de tecnologias inovadoras (Enricone, 2006).

Contudo, os professores demonstraram serem cientes da importância do uso de tecnologia na escola (Questão 18). Entre os relatos, destaca-se:

"A tecnologia serve para tornar mais transparente os conteúdos, facilitar o aprendizado; "Melhorar e aprimor o processo de ensino-aprendizagem; "Ferramentas para transformar as informações em formações"; "Trazer novas informações, atualizar o conhecimento e facilitar o processo ensino- 
aprendizagem"; "Se tivéssemos internet, teríamos mais recursos para trabalhar em sala de aula; facilitar, espírito critico, pesquisa (capacidade), conhecimentos novos";

Os professores mencionaram também as dificuldades encontradas no uso das TIC em sala de aula, entre elas, destaca-se (Questão 19):

"Não sei preparar aula usando a tecnologia"; "Não temos internet $e$ pessoas capacitadas para auxiliar ou preparar certas atividades na informática"; "Eu não domino totalmente o uso da tecnologia”; "A maior dificuldade é que eu tenho pouco conhecimento sobre TIC, não tenho curso";

Ainda, apenas $19 \%$ dos professores consideram-se capazes de gerar conteúdos e disponibilizá-los na internet e $12 \%$ possuem acesso a conteúdos digitais e ferramentas de caráter didáticos/pedagógicos para uso efetivo em sua matéria (Questões 20 e 21).

Considerando que a escola atende os alunos quilombolas, também foi perguntado como os professores abordam a cultura quilombola em sua disciplina (Questão 22). Os professores mencionaram textos, interpretação, danças, obras de arte, pintura, desenhos, filmes, pesquisas, entre outras.

Ressalta-se que a cultura quilombola faz parte da escola, os conteúdos são pensados levando em conta a realidade da comunidade, entretanto a falta da internet limita a divulgação dos trabalhos desenvolvidos sobre essa comunidade, bem como a pesquisa sobre outras comunidades. Nesse contexto, para que a inclusão digital se realize, não basta que a sociedade obtenha o conhecimento sobre estes grupos, mas também que os estudantes quilombolas se vejam dentro da sociedade atual.

A inserção de tecnologias no processo de ensino-aprendizagem exige muito mais do que a simples adaptação das formas tradicionais de ensino aos novos equipamentos, sobretudo requer uma nova pedagogia que favoreça tanto o aprendizado personalizado quanto o cooperativo em rede. Entretanto, para que a potencialidade informativa e comunicativa das redes possa ser explorada é necessário que os professores estejam minimamente familiarizados com essas tecnologias e suas possibilidades pedagógicas, neste sentido, é fundamental a redefinição do papel do professor (Kenski 2003), além de terem acesso à internet.

\section{Conclusão}

O uso das tecnologias da informação e da comunicação no ensino de estudantes de comunidades quilombolas representa um desafio aos professores, pois exige capacitação adequada para permitir a potencialização, a integração, o envolvimento e o compromisso social, assegurando a formação de um cidadão participativo e comprometido com sua aprendizagem e com o grupo social no qual está inserido.

Para tal, é necessário que se amplie as políticas públicas educacionais que visem atender aos problemas específicos desse espaço, respeitando e considerando as diversidades e as especificidades dos remanescentes de quilombos. Ainda, é preciso que a Universidade se volte para essas comunidades incentivando projetos multidisciplinares de pesquisa, ensino e extensão que resultem em maior conhecimento sobre as peculiaridades dessas comunidades e em ações concretas no que diz respeito ao fomento das TIC na capacitação de professores e de pessoal técnico-administrativo e em intervenções diretas com os estudantes quilombolas.

A partir da Universidade, estudantes de iniciação científica e pós-graduações podem desenvolver seus projetos de pesquisa com essa temática. Nas áreas de ensino 
deve ser incentivado que os estágios curriculares supervisionados sejam realizados em escolas quilombolas e, colaborativamente, com os docentes da escola sejam criados planos de ensino e de aula visando o uso das TIC.

Além disso, as verbas advindas de projetos desenvolvidos por grupos de pesquisa podem ser utilizadas para compra de materiais e equipamentos para a escola, facilitando o uso das TIC pelos professores da comunidade, entre muitas outras ações.

Ressaltamos que este trabalho faz parte de um projeto maior que pretende investigar também estudantes e pais da comunidade quilombola São Miguel e da Escola Municipal Manuel Albino Carvalho quanto ao uso das TIC em sala de aula. Ao pontuar os principais problemas enfrentados sobre essa questão, ações colaborativas com a comunidade escolar quilombola serão desenvolvidas tal como citado no parágrafo anterior.

Assim, os membros das comunidades quilombolas, enquanto convivem cultivando sua cultura, não serão deixados à margem da sociedade sem terem a oportunidade de conhecer, experimentar e se apropriar criticamente das tecnologias da informação e da comunicação. Nesse contexto, o uso das TIC na escola pode incentivar que o povo quilombola não seja apenas um receptor do conhecimento institucionalizado, mas agente na construção desse conhecimento, preservando, assim, aspectos culturais da comunidade e possibilitando a interação destas com outras geograficamente inacessíveis para o necessário resgate da cultura afro.

\section{Referências Bibliográficas}

ALMEIDA, M.E.B; PRADO, M.E.B.B. (2009). Integração tecnológica, linguagem e representação. Disponível em: $\underline{\text { http://midiasnaeducacao- }}$ joanirse.blogspot.com/2009/02/integracao-tecnologica-linguagem-e.html

Acesso:out/2011.

ALMEIDA, F.; VALENTE, J.A. (2009). Visão Analítica da Informática a Educação no Brasil: A Questão da Formação do Professor. Disponível em: <http://www.proinfo.gov.br>. Acesso em: 11 jun.

AQUINO, M. A. (2008). O novo status da informação e do conhecimento na cultura digital. Informação \& Sociedade: Estudos, João Pessoa, v. 18, n. 1, p. 79 - 100.

CAVALCANTE, A.V.B.; NETO, C..E.S.; FERREIRA, J.S.; SOUZA, F.F. (2009). Letramento Digital - O Caso Caiana dos Crioulos. Revista África e Africanidades - Ano 2 - n. 7 - Novembro.

COSTA, R.L; THEREZA JR., A.H.; GOMIDE, R.S.; GOMIDE, R.V.S.; DAMASCENO, E.F. (2007). Informática Básica nas Escolas Públicas Buscando a Inclusão Digital dos Estudantes da Oitava Série do Ensino Fundamental em diante e da Comunidade em Geral. Anais... do Workshop de Informática na Escola. Disponível: http://www.de9.ime.eb.br/ sousamaf/cd/pdf/arq0051.pdf. Acesso em março de 2012.

ENRICONE, D. (2006). A dimensão pedagógica da prática docente futura. In: ENRICONE, D. (orgs). A docência na educação superior- sete olhares. Porto Alegre: Evangraf,

FREIRE, P. (2006). Pedagogia do Oprimido. São Paulo: Paz e Terra,

GIL, A.C. ( 2002). Como elaborar projetos de pesquisa. 4. ed. São Paulo: Atlas.

GÓMEZ, A.I.P. (1998). As funções sociais da escola: da reprodução à crítica do conhecimento e da experiência. In: SACRISTÁN, J. G. e GOMEZ, A.L.P. Compreender e transformar o ensino. São Paulo: Artmed, p.13-26. 
KENSKI, V. M. (2003). Tecnologia e as Alterações no Espaço e Tempo de Ensinar e Aprender. São Paulo: Papirus.

KENSKI, V.M. (2010). Educação e tecnologias o novo ritmo da informação. Campinas: Papirus, 6 ed. v.1. 141 p.

MARTINSI. M.C. (2008). Situando o uso da mídia em contextos educacionais. Disponível em: http://midiasnaeducacao-joanirse.blogspot.com/2008/12/situandoo-uso-da-mdia-em-contextos.html Acesso:out/2011.

PARÉ, M.L.; OLIVEIRA, L.P.; VELLOSO, A.D. (2007). A educação para quilombolas: experiências de São Miguel dos Pretos em Restinga Seca (RS) e da Comunidade Kalunga do Engenho II (GO). Cad. Cedes, Campinas, vol. 27, n. 72, p. 215-232, maio/ago. Disponível em <http://www.cedes.unicamp.br>. Acesso: dez/2011.

ROSINI, A.M. (2007). As novas tecnologias da informação e a educação à distância. São Paulo:Cengage Learning,

SACRISTÁN, J.G., GÓMEZ, A. I. Pérez. (1998). Compreender e transformar o ensino. Porto Alegre: ARTMED Editora.

SAMPAIO, M.N; LEITE, L.S. (1999). Alfabetização tecnológica do professor. 5. ed. Petrópolis: Vozes.

SILVA, M.N.S. (2007). Formação do Professor, pedagogia de projetos e as tecnologias da informação e da comunicação. Práxis Educacional. Vitoria da Conquista: Edições Uesb, v. 3, p. 109-126.

SOFFA, M.M.; TORRES, P.L. (2009). O processo ensino-aprendizagem mediado pelas tecnologias da informação e comunicação na formação de professores on-line. IX Congresso Nacional de Educação. Disponível: http://www.pucpr.br/eventos/educere/educere2009/anais/pdf/3285_1440.pdf Acesso: março/2012. 